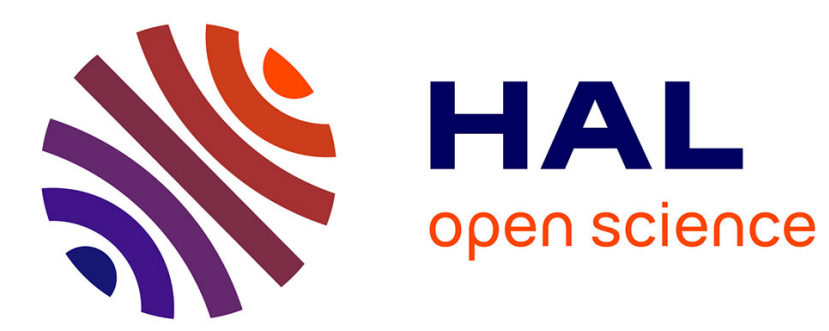

\title{
A TRANSIENT GRATING STUDY OF ACOUSTIC PROPERTIES OF POLYMER MATERIALS
}

Dominique Blanchard, R. Casalegno, M. Pierre, H. Trommsdorff

\section{To cite this version:}

Dominique Blanchard, R. Casalegno, M. Pierre, H. Trommsdorff. A TRANSIENT GRATING STUDY OF ACOUSTIC PROPERTIES OF POLYMER MATERIALS. Journal de Physique Colloques, 1985, 46 (C7), pp.C7-517-C7-521. 10.1051/jphyscol:1985792 。 jpa-00225122

\section{HAL Id: jpa-00225122 https://hal.science/jpa-00225122}

Submitted on 1 Jan 1985

HAL is a multi-disciplinary open access archive for the deposit and dissemination of scientific research documents, whether they are published or not. The documents may come from teaching and research institutions in France or abroad, or from public or private research centers.
L'archive ouverte pluridisciplinaire HAL, est destinée au dépôt et à la diffusion de documents scientifiques de niveau recherche, publiés ou non, émanant des établissements d'enseignement et de recherche français ou étrangers, des laboratoires publics ou privés. 
JOURNAL DE PHYSIQUE

Colloque C7, supplément au $n^{\circ} 10$, Tome 46 , octobre 1985

page $\mathrm{C} 7-517$

\title{
A TRANSIENT GRATING STUDY OF ACOUSTIC PROPERTIES OF POLYMER MATERIALS
}

\author{
D. Blanchard, R. Casalegno, M. Pierre and H.P. Trommsdorff \\ Laboratoire de Spectrométrie Physique ${ }^{+}$, Université Scientifique et Médicale de \\ Grenoble, B.P. 87, 38402 Saint-Martin d'Hères Cedex, France
}

\begin{abstract}
Résumé - La technique des réseaux transitoires constitue une méthode très sensible pour l'étude de nombreux phénomènes de relaxation et de transport en phase condensée. Elle permet de produire, avec des impulsions lumineuses courtes, des phonons monochromatiques de haute fréquence, puis de suivre leur évolution. Elle offre ainsi une méthode adaptée à la mesure des propriétés acoustiques (propagation et atténuation) de matériaux liquides et solides. Dans ce travail cette technique est appliquée à 1'étude d'un polymère (PMMA) au cours de transformations physiques ou chimiques.
\end{abstract}

\begin{abstract}
Transient grating techniques have been established as a very sensitive method to study numerous relaxation and transport properties in condensed phases. With short light pulses coherent ultrasonic phonons can be generated and monitored. Transient grating techniques afford thus a convenient method to measure and to follow acoustic (propagation and damping) properties of $1 i-$ quid and solid materials. In this work this technique is used to study the transformation of a polymer material (PMMA) undergoing physical and chemical transformations.
\end{abstract}

\begin{abstract}
INTRODUCTION
Acoustic properties of polymer materials have been widely studied by conventional methods using tranducers to produce and to detect the acoustic waves. These methods become obviously inapt when the properties of the polymer make it difficult to establish a good mechanical contact with the tranducer or when the acoustic attenuation becomes so high that the wave is damped over a few cycles only. These situations arise however when the material undergoes the most interesting transformations : one example is the glass-rubber transition as a function of temperature, an other is the transformation from monomer to polymer during the polymerization.
\end{abstract}

It is the purpose of this work to demonstrate the usefulness of a purely optical method to induce and monitor coherent acoustic phonons. The interference of two crossed laser beams of equal frequency produces a spatially periodic excitation of the sample which in turn leads to an index grating of the same periodicity. The temporal evolution of this grating is probed by the diffraction of a third beam. This transient grating method is well established and has been used to monitor a variety of dynamical processes in condensed phases $/ 1 /$. When the duration of the exciting laser pulses is short with respect to the period of a sound wave with wavelength equal to the grating spacing the impulsional excitation of the material creates a standing acoustic wave $/ 2 \%$. The spatial-temporal density variations linked with this wave contribute in turn to the evolution of the index grating and are probed by the timedelayed pulse. The frequency and damping of an ultrasonic wave are thus measured within a small volume inside the sample and all the problems of interfaces and sample size existing in the conventional methods mentioned above are eliminated.

In this work we apply these techniques to the study of the two aformentioned transformations of: a specific polymer material. : PMMA.

tassocié au C.N.R.S. 


\section{EXPERIMENTAL}

The experimental set up is given in fig. 1. A cw pumped $\mathrm{Nd}^{3+}$ :YAG laser is acoustooptically Q-switched and mode-locked, and delivers at a repetition rate of $500 \mathrm{~Hz}$ trains of light pulses of 120 ps duration. The frequency doubled $532 \mathrm{~mm}$ pulse train is used to synchronously pump a cavity dumped dye laser. The single pulses at $\sim 560$ $\mathrm{nm}$ have a duration of about $25 \mathrm{ps}$ and an energy of $15 \mu \mathrm{J}$; they are split into three beams. Two time coincident pulses $E_{1}$ and $E_{2}$ of equal amplitude are crossed in the sample ; the third probe pulse $E_{3}$ is time delayed. One of the exciting beams is chopped at half the pulse repetition rate and the signal detected at this frequency is fed into an $x-y$ recorder, the $x$ of which is directly proportional to the reflector position of the delay line.

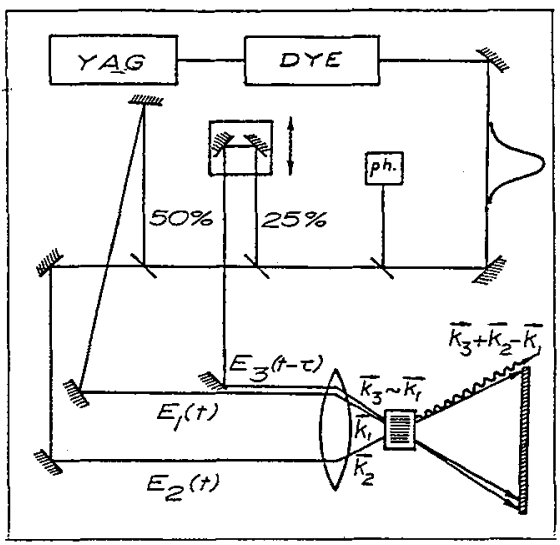

Fig. 1 - Experimenta1 set up

\section{MATERIALS}

High quality PMMA samples were provided by Röhm G.m.b.H. They were colored by a non-fluorescing dye which, in the samples of $3 \mathrm{~mm}$ thickness, absorbed $60 \%$ of the light at the frequencies of the incident laser beams. In order to avoid local heating by the laser beams, the sample was rotated at 500 r.p.m. inside a temperature regulated oven. Measurements during the polymerization where done in a rotating cell. The monomer was colored with $5 \cdot 10^{-4}$ mole/l of malachite green. The polymerization was initiated by adding $0.1 \%$ of AIBN and maintaining the sample at $40{ }^{\circ} \mathrm{C}$.

\section{GENERATION OF ULTRASONIC WAVES}

The fringe spacing in the sample is given by $\Lambda=\lambda / 2 \sin (\Theta / 2)$ where $\lambda$ and $\theta$ are the wavelength and the angle between the $E_{1}$ and $E_{2}$ beams respectively measured in the air outside of the sample.

In a non-absorbing medium the light field is coupled to the material by electrostriction but the distortion of the medium is small in this case and the generation of the acoustic wave is not very efficient, resulting in poor signal to noise ratios.

A more efficient coupling / $3 /$ is obtained by doping the material with a suitable dye : if the non-radiative deexcitation of the dye is very efficient its lifetime will be short and virtually all the absorbed energy will be dumped as heat into the medium on the time scale of the laser pulse duration. This spatially periodic heating of the sample leads to a corresponding compression and is the source of the standing acoustic wave. In the limit that the excitation process is short compared with the period of the acoustic wave and that the spatial extent of the excitation is large with respect to the grating period, the time evolution of the grating is described by $/ 2 / 4 /$ : 


$$
n=A\left(1-e^{-\gamma t} \cos 2 \pi f t\right)^{2}
$$

where $\eta$ is the diffraction efficiency, $\gamma$ the damping constant and $f$ the frequency of the acoustic wave. Heat diffusion as well as the build-up of a permanent thermal grating due to slower relaxation processes and to the damping of the acoustic wave are neglected in this expression (see below).

All experiments were performed with $\theta \approx 20^{\circ}$ resulting in a phonon wavelength of 1.6 $\mu$ and frequencies between 1 and $2 \mathrm{GHz}$. The measurement of the period $\mathrm{T}$ gives directly the corresponding speed of sound $v=\Lambda / T$. Expression (1) shows that the amplitude of signal maxima do not decay exponentially even if the acoustic waves are exponentially damped out.

VARIATION OF SOUND VELOCITY AND ATTENUATION IN PMMA AROUND THE GLASS-RUBBER TRANSITION

\section{PMMA}

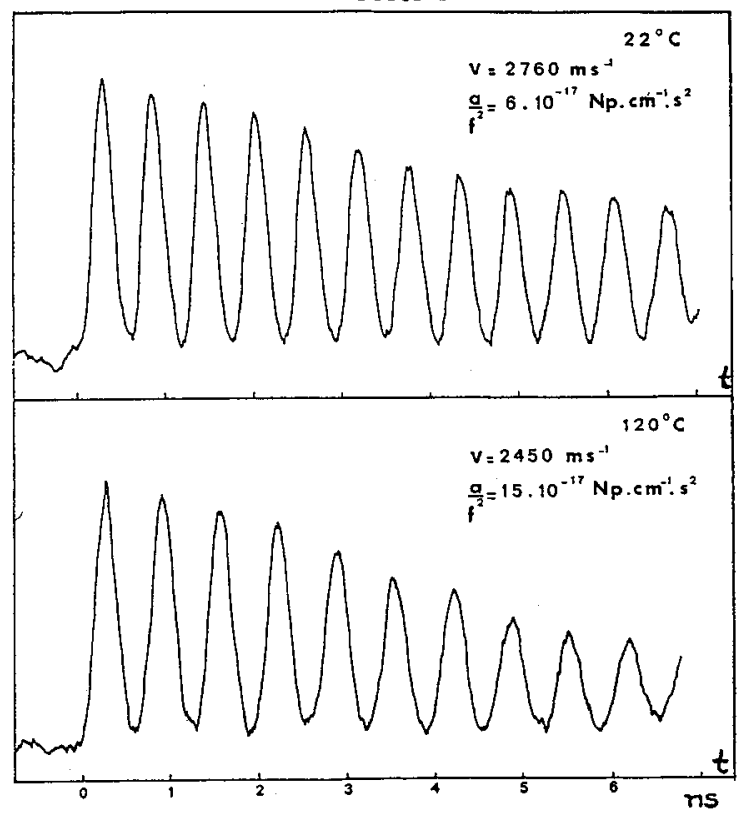

Fig. 2 - The time evolution of a standing ultrasonic wave in PMMA at $22{ }^{\circ} \mathrm{C}$ and $120{ }^{\circ} \mathrm{C}$.

Above $100{ }^{\circ} \mathrm{C}$ PMMA begins to undergo a glass-rubber transition for which the critical zone ranges over more than $100{ }^{\circ} \mathrm{C}$. Fig. 2 shows two typical recordings at $22{ }^{\circ} \mathrm{C}$ and $120^{\circ} \mathrm{C}$, and fig. 3 summarizes al1 results obtained between room temperature and 150 ${ }^{\circ} \mathrm{C}$. The velocity of sound is rapidly decreasing above $105^{\circ} \mathrm{C}$, the glass-rubber transition temperature, while the acoustic attenuation characterized by $\alpha / f^{2}$, with $\alpha=$ $\gamma / v$, is increasing rapidly. While the evaluation of the sound velocity can be done with a precision better than $1 \frac{\circ}{\circ}$, and the numerical values obtained are reproducible for different samples, the measurement of the attenuation is more problematic at higher temperatures. The observed signals no longer follow formula (1) : an increase of the base line is observed indicating the appearance of a permanent grating. In addition the magnitude of the damping depends upon the sample and more specifically upon its thermal history. These effects are indicative of slower (as compared with the laser pulse duration and the acoustic period) processes releasing energy at longer times after the excitation; possible sources are the creation and recombination of radicals and the release of elastic energy stored in the polymer coils : clearly these phenomena require a more detailed study. 


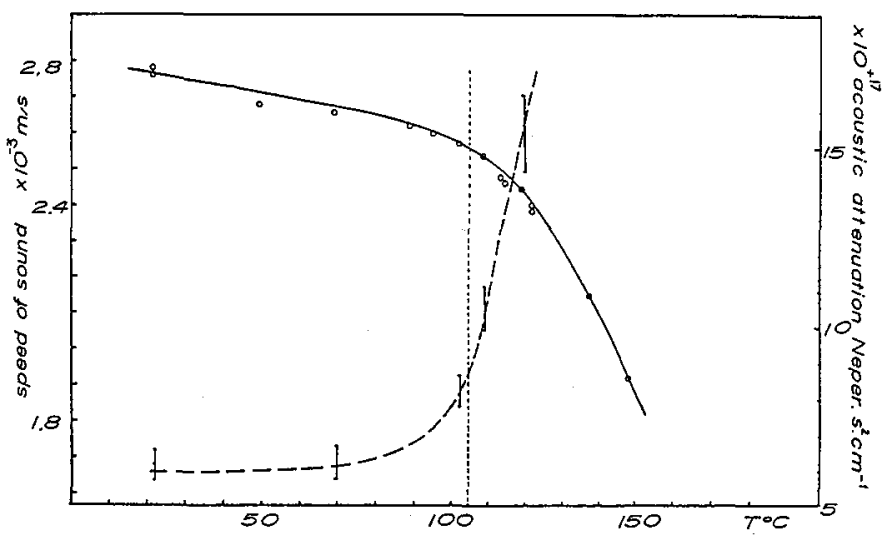

Fig. 3 - Variation of the speed of sound and of the acoustic attenuation in PMMA as a function of temperature between $22{ }^{\circ} \mathrm{C}$ and $150{ }^{\circ} \mathrm{C}$. The dashed vertical line marks the onset of the glass-rubber transition.

\section{VARIATION OF THE ACOUSTIC PROPERTIES DURING THE POLYMERIZATION OF MMA}

This study demonstrates the possibility of measuring acoustic properties in amedium which is undergoing a polymerization. Fig. 4 shows the increase of the speed of sound from $1225 \mathrm{~m} / \mathrm{s}$ in the monomer, a typical value for an organic 1iquid, to 2760 $\mathrm{m} / \mathrm{s}$ in the polymer. This increase is monotonic and can therefore be used to evaluate the degree of polymerization. The corresponding variation of the damping is more interesting in passing through a maximum value at intermediate degrees of polymerization.

Fig. 4 - The time evolution of a standing ultrasonic wave in MMA during polymerization.

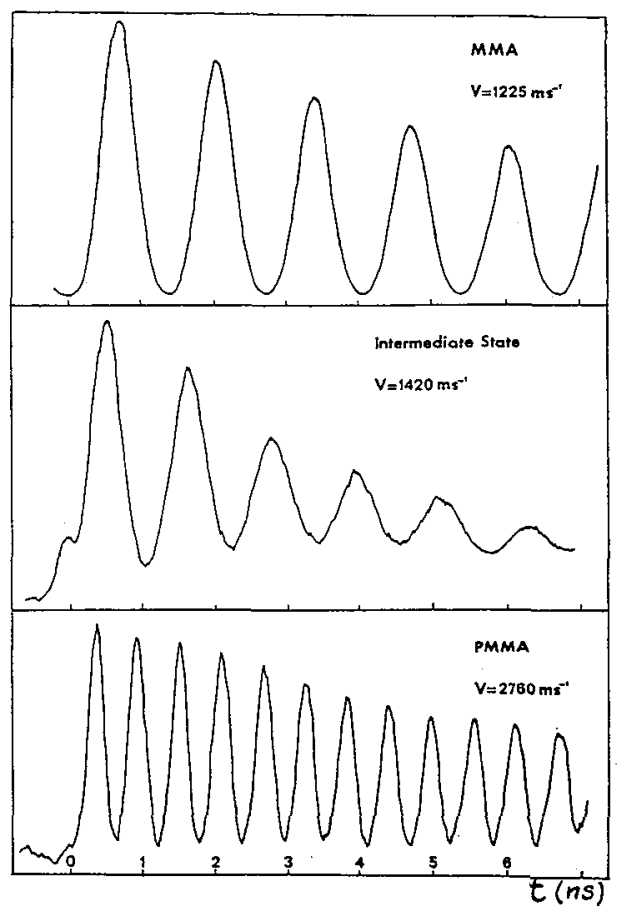




\section{CONCLUSION}

This study shows that picosecond laser techniques are suitable to measure acoustic properties of samples undergoing physical and/or chemical changes making them difficult or impossible to study by conventional methods. The technique is particularly powerful when the damping becomes important and the acoustic wave is damped over a few microns.

The application to PMMA exposes the large variation of the velocity and the damping of ultrasonic waves as a function of temperature across the glass-rubber transition and as a function of the degree of polymerization.

Further applications of these techniques include the study of the swelling of polymer materials in solvants, their degradation at high temperatures and the study of diphasic materials such as PMMA/PBA presently underway.

\section{ACKNOWLEDGEMENT}

We would like to thank Dr. W. Wunderlich from Röhm G.m.b.H., Darmstadt, for providing us with most of the samples used in this study and for helpful advice. D.B. is grateful to Dr. Gandini for introducing him into the art of polymerization.

\section{REFERENCES}

/1/ Ippen, E. P. and Shank, C. V., Ultrashort light pulses, S.L. Shapiro Editor, Springer Verlag (1977) 111.

/2/ Nelson, K. A., Fayer, M. D., J. Chem. Phys. 72 (1980) 5202.

13/ Miller, R. J. D., Casalegno, R., Nelson, K. A., Fayer, M. D., Chem. Phys. 72 (1982) 371.

14/ Desai, R. C., Levenson, M. D., Barker, J. A., Phys. Rev. A 27 (1983) 1968. 